\title{
Arquivos Brasileiros de Cardiologia
}

Setembro de 1997 - Volume 69 - Número 3

\section{Simpósio "ABC" Ecocardiografia Fetal}

Editora convidada - Solange Bernardes Tatani

\section{SUMÁRIO}

Apresentação .

Introduction

Solange Bernardes Tatatani

Ecocardiografia fetal. Apresentandoo método .....

Fetal echocardiography. Presenting the method

Solange Bernardes Tatani

Ecocardiografia fetal. Novas fronteiras

Fetal echocardiography. New frontiers

Antonio Carlos Carvalho

Fisiologia da circulação fetal e diagnóstico das alterações funcionais do coração do feto

196

197 203 


\section{Apresentação}

Atualmente já é possível pensar em intervenções cirúrgicas e não cirúrgicas no coração do feto, sem prejuízo do seu desenvolvimento intra-uterino. Fato que torna evidente a importância do diagnóstico completo e preciso das alterações cardiovasculares fetais. A ecocardiografia fetal permite a identificação da anatomia, da função e do ritmo cardíacos normais, possibilitando o diagnóstico de distúrbios no sistema cardiovascular no período pré-natal.

O objetivo deste simpósio é mostrar o coração fetal normal e as possibilidades diagnósticas de alterações no coração do concepto por intermédio da ecocardiografia fetal e o impacto do método para a neonatologia. Aos colaboradores, nossos agradecimentos.

\section{Solange Bernardes Tatani}

Centro de Cardiologia Não Invasiva

São Paulo, SP 